\title{
CPAP Added to Oxygen Administration Avoid Intubation in Acute Respiratory Distress in COVID-19 Pneumonia. Case Report
}

\author{
Gimbada Benny Mwenge ${ }^{1}$ (D) $\cdot$ Daniel Rodenstein $^{1}$
}

Accepted: 8 June 2020 / Published online: 18 June 2020

(C) Springer Nature Switzerland AG 2020

\begin{abstract}
It was recently described that COVID-19 pneumonia patients had an atypical form of the ARDS syndrome and required gentle ventilation. We report here on benefits of CPAP treatment in a patient with COVID-19 pneumonia. A 63-year-old patient of African origin presented to the emergency room with COVID-19 pneumonia. Fever had started 5 days before her admission. On day 4, rapid clinical deterioration associated to a high respiratory rate and increased oxygen requirements was noted. The patient was working in an intensive care unit and refused to be intubated. Oxygen was administered at a rate of 15 litres per minute via a Boussignac valve, which initially restored normal oxygen saturation, but this treatment was poorly tolerated and the patient withdrew it after $2 \mathrm{~h}$. A CPAP set at a pressure of $8 \mathrm{~cm}$ of water (Goodknight ${ }^{\circledR}$ ) was then introduced with better tolerance, allowing the patient to wear it almost continuously for more than $38 \mathrm{~h}$. The patient also benefited from the administration of methypredinsolone $40 \mathrm{mg}$. Concerning tolerance, a substantial advantage was noted for CPAP machine compared to the Boussignac valve with in addition, a clear decrease in respiratory rate. We would like to encourage the use of CPAP, better tolerated for extended hours with lower oxygen flows, in patients with COVID-19 pneumonia, where acute respiratory distress all too often leads to patient intubation and the genesis of deleterious lung lesions.
\end{abstract}

Keywords COVID-19 pneumonia $\cdot$ ARDS $\cdot$ CPAP

\section{Introduction}

It was recently described that COVID-19 pneumonia patients had an atypical form of the ARDS syndrome suggesting instead hyperperfusion of gasless alveolar tissue. Increased oxygenation could be achieved through the redistribution of perfusion in response to an applied positive pressure and/or gravitational forces in these patients. Thus, the lowest possible PEEP and gentle ventilation were proposed in these patients [1]. Gentle ventilation systems have often been used in the literature in the management of acute respiratory failure to improve oxygen delivery. Some authors have demonstrated that the use of CPAP through a Helmet mask in the ARDS has prevented intubation in a significant number of patients

This article is part of the Topical Collection on Covid-19

Gimbada Benny Mwenge

Gimbada.mwenge@uclouvain.be

1 Pneumology Department and Center for Sleep Medicine, Cliniques Universitaires Saint Luc, Avenue Hippocrate 10,

1200 Brussels, Belgium
[2]. The Boussignac CPAP [3], which is a disposable and inexpensive system, has also shown a reduction in the rate of intubation in acute respiratory failure related to cardiogenic edema [3]. In our center, the absence of necessary sterilization (disposable device) made it preferable to the conventional CPAP, which risked being "condemned" due to difficulties of guaranteed sterilization .

However, clinical illustrations in the case of management of acute respiratory failure of pneumonia COVID-19 are missing in the literature. Clinicians should know the benefits and modalities of this type of treatment on the management of COVID-19 pneumonia.

We wish to report here on the possible benefits of CPAP treatment in a patient with COVID-19 pneumonia.

\section{Patient Information}

A 63-year-old patient of African origin presented to the emergency room following an influenza-like illness that had started 5 days earlier with persistent fever up to $39.2{ }^{\circ} \mathrm{C}$ at home. The patient was working in an intensive care unit and had been in 
contact with patients with COVID-19 pneumonia. Other symptoms were dry cough, rhinorrhea, sore throat, agueusia, and unusually severe headache. No NSAIDs, ACE inhibitors/ sartans, or corticosteroids. Previous medical history included systemic hypertension controlled with Amlopdipine, type II diabetes treated with Metformin, well-controlled hypothyroidism, and grade 2 obesity.

High-resolution chest CT scan revealed extensive ground glass opacities occupying more than $50 \%$ of the pulmonary parenchyma. Biology revealed a mild inflammatory syndrome with a CRP of $43 \mathrm{mg} / \mathrm{dl}$ with no hematological abnormalities. A PCR performed on nasopharyngeal smear was positive for SARS-CoV-2. The patient had fever up to 2 days after admission $\left(38.9^{\circ} \mathrm{C}\right)$ and then remained apyretic. Oxygen saturation was $95 \%$ with 21 oxygen $(\mathrm{FIO} 2=28 \%)$ administered by nasal prongs.

\section{Treatments and Outcomes}

She was started on hydrochloroquine for 5 days.

On day 3 after admission (i.e., D8 after onset of symptoms), tachypnea developed at 35 per minute and oxygen requirements increased with 4-6 1 administered by oxygen mask $(\mathrm{FIO} 2=50 \%)$ for an oxygen saturation of $93 \%$. The evolution of the measured oxygen saturation, the respiratory rate, and the mechanical supports is summarized in Table 1.

On day 4 faced with increasing dyspnea, 15 liters per minute oxygen was administered via a Boussignac valve and a facial mask in order to create a small positive pressure (a HEPA filter was placed in front of the expiratory leak in order to limit the aerosolization in the room) (see Fig. 1). However, our patient, although willing to accept the treatment, did not tolerate it, with a daily use of the Boussignac valve for only $2-$ $3 \mathrm{~h}$ per day.

Oxygen saturation measured by pulse oximeter with the Boussignac valve was then $97 \%$, and the respiratory rate decreased too. Unfortunately, this saturation was not maintained when the patient removed her mask. There was a drop in oxygen saturation when measured under $61\left(\mathrm{FIO} 2,50 \%^{\circ}\right)$ of administered oxygen.

On day 6 a sudden deterioration was observed; an increase in oxygen requirements and a very significant increase in the inflammatory syndrome were observed with a CRP $175.2 \mathrm{mg} /$ $\mathrm{dl}$ (see Table 1). There was no neutrophil hyperleukocytosis, and the patient was apyretic. Respiratory alkalosis $\left(\mathrm{pCO}_{2}=\right.$ $27 \mathrm{mmHg}$ ) and hypokalemia ensued. Saturation measured on ambient air was $82 \%$. With 101 of supplemental oxygen $(\mathrm{FIO} 2=99 \%)$ the measured saturation was $93 \%$. The respiratory rate was 44 per minute without the Boussignac valve. To try to increase the time on positive pressure, the Boussignac valve was replaced by a CPAP machine (Gooknight ${ }^{\circledR}$ device) started at a pressure of $8 \mathrm{~cm} \mathrm{H}_{2} \mathrm{O}$ via the same nasal-oral mask, with a leak in the connection nozzle to the mask equipped with a HEPA filter and oxygen flow of 12 liters per minute. The patient's respiratory rate fell to 22 per minute. CPAP was maintained almost continuously except for drinking water. Oxygen saturation measured with CPAP was $98 \%$. The treatment was well tolerated; the patient was placed in the prone position for as long as she tolerated it. Azithromycin was started. After $48 \mathrm{~h}$, administration of corticosteroids (Solu-Medrol $(0.5 \mathrm{mg} / \mathrm{kg})$ ) was followed by a decrease in the CRP to $19 \mathrm{mg} / \mathrm{dl}$.

After 5 days of treatment, the CPAP treatment could be completely weaned; the total duration of use of the machine during this period was 38 consecutive hours followed by another $20 \mathrm{~h}$ and then 2 nights of $8 \mathrm{~h}$.

The patient showed no further deterioration and could be discharged home.

\section{Discussion}

In our patient, it seems that the positive pressure added to oxygen administration allowed for a safe oxygen saturation level, that oxygen alone could not grant. Indeed, our patient was receiving $99 \%$ oxygen with an oxygen saturation of $91 \%$ when her clinical condition deteriorated. Six-day CPAP was instrumental in buying time while the patient recovered. At the end of this period of CPAP use, she required only $24 \%$ oxygen.

A group of Italian physicians reported that a cohort of COVID-19 patients, suffering from acute respiratory distress syndrome, had a dissociation between their relatively well preserved lung mechanics and the severity of hypoxemia, which they called "atypical" for ARDS [1]. Taking into account this observation and that high PEEP in a poorly recruitable lung tends to result in severe hemodynamic impairment and fluid retention, the content of this manuscript and described patient management are consistent with data and supported by evidence.

This clinical illustration about the benefits and modalities of a treatment with CPAP is helpful and sustains the possibility of gentle ventilation for the management of COVID-19 pneumonia. Anyway, in patients who are treated with continuous positive airway pressure or noninvasive ventilation and who present with clinical signs of excessive inspiratory efforts, intubation should be prioritized to avoid excessive intrathoracic negative pressures and self-inflicted lung injury, beyond any patient preference or tolerance [4].

Concerning tolerance, a substantial advantage was noted for CPAP machine compared to the Boussignac valve with in addition, a clear decrease in respiratory rate indeed studies using CPAP Boussignac have been performed in the management of acute respiratory failure related to cardiogenic edema. Boussignac valve was used as a mechanical support in combination with the use of diuretics. The duration of use reported 
Table 1 Evolution over the days of oxygen saturation, oxygen flow of the mechanical support, and drug treatment

\begin{tabular}{|c|c|c|c|c|c|c|}
\hline $\begin{array}{l}\text { Time line } \\
\text { (days) }\end{array}$ & $\begin{array}{l}\text { CRP (mg/ } \\
\mathrm{dl})\end{array}$ & $\begin{array}{l}\text { Oxygen flow } \\
\text { (L/min) }\end{array}$ & $\begin{array}{l}\text { Mechanical support or } \\
\text { mask }\end{array}$ & $\begin{array}{l}\text { Oxygen saturation (\%) } \\
\text { (FIO2) }\end{array}$ & $\begin{array}{l}\text { Respiratory } \\
\text { rate }\end{array}$ & Pharmacological therapy \\
\hline D1 & 22.3 & 2 & Nasal prong & $95(28 \%)$ & 22 & HDX \\
\hline D2 & & 6 & Facial mask & $93(40 \%)$ & 28 & HDX \\
\hline D3 & 47.8 & 6 & $\begin{array}{l}\text { Non re-breather face } \\
\text { mask }\end{array}$ & $94(50 \%)$ & 38 & HDX \\
\hline \multirow[t]{2}{*}{ D4 } & 73.5 & 15 & & & 40 & HDX \\
\hline & & 15 & Boussignac valve * & $97 *(100 \%), 92 * *(50 \%)$ & & \\
\hline D5 & & 15 & Boussignac valve* & $97 *(100 \%), 93 * * *(99 \%)$ & 44 & HDX \\
\hline \multirow[t]{2}{*}{ D6 } & 175.2 & 10 & & 93 & 44 & AZT \\
\hline & & 10 & CPAP $8 \mathrm{~cm} \mathrm{H}_{2} \mathrm{O}$ & 98 & 20 & \\
\hline \multirow[t]{2}{*}{ D7 } & & 10 & & 90 & & \\
\hline & & 8 & CPAP $7 \mathrm{~cm} \mathrm{H}_{2} \mathrm{O}$ & 98 & 20 & HDX \\
\hline D8 & 223.2 & 8 & CPAP $7 \mathrm{~cm} \mathrm{H}_{2} \mathrm{O}$ & 98 & 16 & $\begin{array}{l}\text { AZT + corticosteroids } \\
\text { (Methylprednisolon } \\
40 \mathrm{mg})\end{array}$ \\
\hline D9 & & 6 & CPAP $7 \mathrm{~cm} \mathrm{H}_{2} \mathrm{O}$ & 98 & 14 & Corticosteroids \\
\hline D10 & 73.5 & 4 & CPAP $7 \mathrm{~cm} \mathrm{H}_{2} \mathrm{O}$ & 99 & 14 & Corticosteroids \\
\hline D11 & & 2 & CPAP $7 \mathrm{~cm} \mathrm{H}_{2} \mathrm{O}$ & $99(24 \%)$ & & \\
\hline D12 & 19.1 & 1 & Nasal prong & 96 & & \\
\hline D13 & & 0 & & 95 & & \\
\hline
\end{tabular}

*Oxygen saturation measured with Boussignac (tolerated between 2 to $3 \mathrm{~h}$ per day, three sessions of $1 \mathrm{~h}$ )

**Oxygen saturation measured with oxygen alone (6 1 per minute, $50 \%$ )

*** Oxygen saturation measured with oxygen alone (10 1 per minute, $99 \%)$

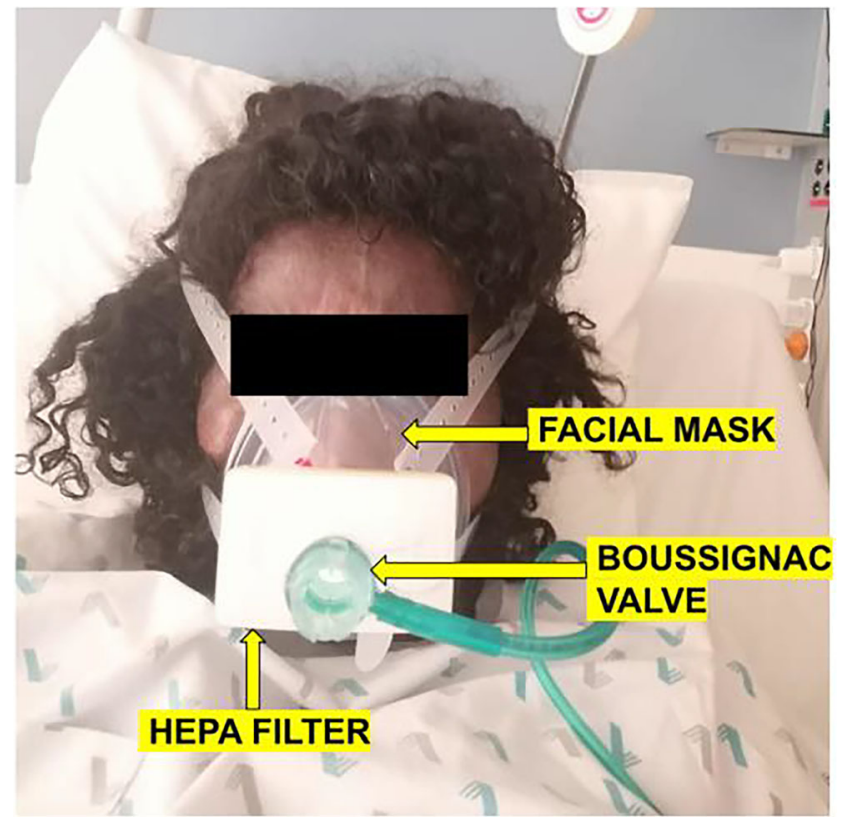

Fig. 1 : This figure shows the patient wearing a face mask. The mask is connected to the Boussignac valve, which is supplied with oxygen through the tube. Note the presence of a Hepa filter to limit the aerosolization of the virus by the authors is often from 2 to $6 \mathrm{~h}$, allowing the action of drug treatment. As mentioned by the authors, the limitations of its use are related to mask tightening, noise, and discomfort. However, conventional CPAP is designed to be used all night long on a regular basis in patients treated for sleep apnea; moreover, the pressure generated is not related to oxygen flow. Improvements have been made by manufacturers since its introduction to improve its tolerance.

Therefore, although the Boussignac valve in the management of acute respiratory failure has not demonstrated any inferiority compared to mechanical ventilation (BPAP) in studies [3], we believe that the need for continuous ventilation of longer duration gives conventional CPAP an advantage. It should be recommended as a first-line treatment. It should be noted that tolerance comparison studies between conventional $\mathrm{CPAP}$ and Boussignac valve are missing in the literature and should be conducted.

However, it is important to emphasize that the administration of corticosteroids has perhaps been beneficial in the evolution of our patient, allowing the patient to pass the clinical milestone of the excessive inflammatory reaction responsible for the phenomena of acute respiratory distress [5]. A retrospective study of 200 patients with ARDS due to COVID-19 apparently showed a lower mortality among those receiving 
methylprednisolone [6]. A recent expert opinion has proposed the administration of glucocorticoids in different stages of COVID-19 infection, due to the adrenal insufficiency and increased immune response characteristic of this virus [7].

In conclusion, this clinical case illustrates the use of CPAP to avoid intubation in a patient with respiratory failure. We would like to encourage the use of CPAP, better tolerated for extended hours with lower oxygen flows, in patients with COVID-19 pneumonia, where acute respiratory distress all too often leads to patient intubation and the genesis of deleterious lung lesions.

\section{Patient Perspective}

The patient was very eager to share her experience; the use of CPAP allowed her to avoid intubation. As a critical care worker, she had seen several patients who had had to be intubated and did not wish to be. She reports that the most important element is to have remained at all times conscious and master of her follow-up.

\section{Compliance with Ethical Standards}

Conflict of Interest The authors declare that they have no conflict of interest.

Informed consent The patient has given her consent for the publication of this article.

\section{References}

1. Gattinoni L, Coppola S, Cressoni M, Busana M, Rossi S, Chiumello D. COVID-19 does not lead to a "typical" acute respiratory distress syndrome. Am J Respir Crit Care Med. 2020;201(10):1299-300. https://doi.org/10.1164/rccm.202003-0817LE.

2. Bhakti K, Wolfe KS, Pohlman AS, Hall JB, Kress JP. Effect of noninvasive ventilation delivered by helmet vs face mask on the rate of endotracheal intubation in patients with acute respiratory distress syndrome:a randomized clinical trial. JAMA. 2016;315(22):243541.

3. Wong DT, Tam AD, Van Zundert TC. The usage of the Boussignac continuous positive airway pressure system in acute respiratory failure. Minerva Anestesiol. 2013;79(5):564-70.

4. Pfeifer M, Ewig S, Voshaar T, et al. Positionspapier zur praktischen Umsetzung der apparativen Differenzialtherapie der akuten respiratorischen Insuffizienz bei COVID-19 [Position Paper for the State of the Art Application of Respiratory Support in Patients with COVID-19 - German Respiratory Society] [published online ahead of print, $2020 \mathrm{Apr} 22$. Pneumologie. 2020. https://doi.org/10.1055/a1157-9976.

5. WangF NJ, Wang H, Zhao Q, Xiong Y, Deng L, Song S, et al. Characteristics of peripheral lymphocyte subset alteration in COVID-19 pneumonia. J Infect Dis. 2020. https://doi.org/10.1093/ infdis/jiaa150.

6. Wu C, Chen X, Cai Y, Xia J, Zhou X, Xu S, et al. Risk factors associated with acute respiratory distress syndrome and death in patients with coronavirus disease 2019 pneumonia in Wuhan, China. JAMA Intern Med. 2020. https://doi.org/10.1001/ jamainternmed.2020.0994.

7. Pofi R, Hasenmajer V, Venneri MA, Sbardella E, Simeoli C, Scaroni C, et al. COVID19 infection and glucocorticoids: update from the Italian Society of Endocrinology Expert Opinion on steroid replacement in adrenal insufficiency. J Endocrinol Invest. 2020:1-7. https:// doi.org/10.1007/s40618-020-01266-w.

Publisher's Note Springer Nature remains neutral with regard to jurisdictional claims in published maps and institutional affiliations. 